\title{
Influence of selected antibiotics on respirometric activity of activated sludge
}

\author{
Dóra Varjúová, Petra Szabová, Igor Bodík \\ Department of Environmental Engineering, Faculty of Chemical and Food Technology, \\ Slovak University of Technology, Radlinského 9, 81237 Bratislava, Slovak Republic \\ dora.varjuova@stuba.sk
}

\begin{abstract}
The main topic of this study is to determine the effect of selected antibiotics on the respirometric activity of sewage sludge microorganisms. Within the practical part of the work, several respirometric measurements were performed with activated sludge from a wastewater treatment plant, while the influence of three selected antibiotics - sulfamethoxazole, sulfapyridine, and ciprofloxacin, on sludge activity was monitored. The aim of the work was to point out the inhibitory effect of all monitored compounds on sludge activity and to quantify the inhibitory effect. For sulfamethoxazole (in the concentration range of $\left.0.142-1.42 \mathrm{mg} \cdot \mathrm{L}^{-1}\right)$, the determined inhibition was in the range of $9.67-27.7 \%$, depending on the concentration of the test substance and the type of respirometric measurements. For sulfapyridine, inhibition values ranged from $1.13 \%$ to $31.9 \%$ for the concentration range from 0.134 to $1.34 \mathrm{mg} \cdot \mathrm{L}^{-1}$. Ciprofloxacin inhibited the activity of activated sludge microorganisms in the range of $4.55 \%$ to $28.8 \%$ (at CPX concentrations from 0.104 to $\left.1.04 \mathrm{mg} \cdot \mathrm{L}^{-1}\right)$.
\end{abstract}

Keywords: activated sludge, antibiotics, inhibition, respirometry, wastewater treatment

\section{Introduction}

Pharmaceutically active compounds (PhACs) are anthropogenic contaminants continuously released into the environment and recognized as contaminants of emerging concern because of their persistent presence in aquatic environments. PhACs are known to be released into aquatic environments through multiple pathways including domestic wastewater, hospital discharges, improper manufacturer disposal, wastewater treatment plants (WWTPs), and water treatment plants (WTPs) (Yang et al., 2017; Mejías et al., 2021). Previous studies have found that removal of PhACs by conventional WWTPs is not sufficient as they can pass through and enter water systems (Golovko et al., 2014; Gago-Ferrero et al., 2017; Sörengård et al., 2019). PhACs are present in surface water, groundwater, drinking water, and sewage at concentrations of parts-per-trillion $\left(\mathrm{ng} \cdot \mathrm{L}^{-1}\right)$ to parts-per-billion $\left(\mu \mathrm{g} \cdot \mathrm{L}^{-1}\right)$ (Dai et al., 2015). However, PhACs removal efficiency of conventional WWTPs is low because the most used treatment system in secondary WWTPs (i.e. activated sludge (AS) process) is originally designed for the removal of easy degradable organic matter (i.e. BOD) and suspended solids to meet the minimum discharge standard (Yang et al., 2017). Although PhACs concentration in sewage influent is relatively low, PhACs that are present as either individual molecules or as complexes may exert considerably toxic or inhibitory effects on activated sludge bacteria, leading to a change in their respirometric activity as well as in their treat- ment abilities (Thomaidi et al., 2015; Thomaidi et al., 2016).

The AS respirometric test is considered as a direct evaluation method for toxic effect of chemicals (e.g. pharmaceuticals) on sludge activity and thus the potential effect on its microbial population and treatment efficacy. Respirometry is a sensitive and cost-effective method based on the consumption of oxygen by AS during biological activities, and has thus been widely used to estimate the potential toxicity of many different chemical compounds (e.g. pharmaceuticals, personal care products, heavy metals, nanoparticles, xenobiotic compounds) on mixed microbial community of WWTP sludge (Vasiliadou et al., 2018). It is worth noting that the presence of toxicants in wastewater streams can affect microbial metabolic and growing activities of bacteria in AS due to their acute and chronic inhibitory effects (Xia et al., 2015; Aydin et al., 2015). Consequently, it has been recently proposed that toxicological tests should not only evaluate the activity of a microbial community but also its microbial diversity. Exposition of bacteria in AS to toxic compounds can affect the quality of the treated effluent in WWTPs. Therefore, the observed differences in pharmaceuticals' removal from WWTPs can be attributed to environmental and operating conditions as well as to differences in the microbial community of WWTPs.

One of the most common respirometry applications is the assessment of toxic or inhibitory effects, due to conventional or emerging pollutants, on biomass. Inhibition is defined as reversible reduction of normal biological functions, while toxicity is related 
to an adverse effect on the biological metabolism, and is commonly irreversible (Spanjers and Vanrolleghem, 2016). Most recent studies focused on the application of respirometry to evaluate toxic or inhibitory effects dealt with acute (i.e. short-term) toxicity (Ortiz de García et al., 2014; Cristóvão et al., 2016; Tominaga et al., 2018; Aguilar et al., 2020; Faria et al., 2021). For example, Aguilar et al. (2020) used respirometric techniques to evaluate the toxic and inhibitory effect of chromium, mercury, lead, zinc, and nickel on the heterotrophic activity of activated sludge. Based on their measurements, the authors found that mercury showed the highest toxicity, producing $100 \%$ inhibition at a concentration of only $7.5 \mathrm{mg} \cdot \mathrm{L}^{-1}$, while nickel was the least toxic with a concentration of $1120 \mathrm{mg} \cdot \mathrm{L}^{-1}$ needed to achieve $50 \%$ inhibition. However, the remarkable study by Vasiliadou et al. (2018) investigated also long-term toxicity effects, providing useful insights on possible issues related to long-term reduction in sludge activity that could be observed in full-scale WWTP operation. Respirometric tests were shown to be useful in evaluation of the toxicity of a wide spectrum of contaminants of emerging concern. However, from the analysis of existing literature, a lack of standardization in the applied protocols and experimental apparatus used for respirometric tests is evident; moreover, according to our knowledge, the potential of this technique in its diverse fields of application (e.g. toxicity assessment, wastewater and biomass characterization) is not fully exploited by researchers and water utilities at present. To the best of our knowledge, despite the high number of respirometry applications in the recent scientific literature, a thorough review on the topic is still missing (Mainardis et al., 2021). This is the reason why we decided to examine the effect of antibiotics on the activity of sewage sludge in order to quantify the degree of inhibition of these substances on the activity of activated sludge microorganisms.

\section{Material and Methods}

In the experimental part of the work, respirometric measurements were done to define the influence of selected antibiotics (ATB) on the activity of sewage sludge. Three pharmaceutical compounds were selected as target chemicals, each belonging to another group of antibiotics: sulfamethoxazole (SMX, $\left.\mathrm{C}_{10} \mathrm{H}_{11} \mathrm{~N}_{3} \mathrm{O}_{3} \mathrm{~S}\right)$, sulfapyridine (SP, $\left.\mathrm{C}_{11} \mathrm{H}_{11} \mathrm{~N}_{3} \mathrm{O}_{2} \mathrm{~S}\right)$, and ciprofloxacin (CPX, $\left.\mathrm{C}_{17} \mathrm{H}_{18} \mathrm{FN}_{3} \mathrm{O}_{3}\right)$. All the chemicals used were purchased from Sigma-Aldrich. Stock solutions were prepared in distilled water. Concentrations of stock solutions and the structural formulas of studied antibiotics are given in Tab. 1.

For a series of respirometric measurements, activated sludge (AS) from the WWTP Bratislava Devínska Nová Ves was used. However, it should be

Tab. 1. Structural formulas and concentrations of prepared antibiotics stock solutions.



${ }^{1}$ Structural formulas of the antibiotics were taken from the website: https://go.drugbank.com/. 
noted that the real concentrations of antibiotics at WWTPs (e.g. at WWTP Bratislava - Devínska Nová Ves, the average concentration of sulfamethoxazole was approximately $400 \mathrm{ng} \cdot \mathrm{L}^{-1}$ and of sulfapyridine it was $370 \mathrm{ng} \cdot \mathrm{L}^{-1}$ in 2016-2017 (Szabová et al., 2021)) are much lower than the concentrations of antibiotics in the respirometric vessel. This means that concentration of the monitored antibiotics in the respirometric vessel is by $10^{3}-10^{4}$ higher than the actual concentration of these antibiotics in wastewater. However, due to the relatively high values of inhibition measured at our chosen antibiotic concentrations, a certain degree of inhibition even at lower antibiotic concentrations can be assumed. At the beginning of each measurement, AS was diluted in a respirometer to the sludge concentration $X_{c}=(0.5-1.5) \mathrm{g} \cdot \mathrm{L}^{-1}$ with water at the same $\mathrm{pH}$ and ionic strength as in the AC process. AS concentration was determined using MB27 moisture analysers from the manufacturer OHAUS. Gravimetric analysis of dry matter concentration of activated sludge using an MB27 moisture analyser was started by test preparation. In the first step, drying temperature was set to $105^{\circ} \mathrm{C}$ and the drying time to AUTO mode. Empty test pan on analytical balances was weighted. A pan handler with an empty test pan was then placed on the pan support and the pan weight was zeroed out. Then, $15 \mathrm{~mL}$ of activated sludge sample were transferred onto the test pan and the heater cover was closed to start the test. At the end of the test, the test pan was placed in a desiccator and weighted after cooling. The result was calculated as the weight of the empty test pan minus the weight of the test pan after cooling divided by the sample volume. Respirometric tests were performed in a respirometric chamber with the volume of $300 \mathrm{~mL}$, while the activation mixture in the vessel was stirred with a magnetic stirrer during the measurement. Before each measurement, AS in the respirometer was aerated to an oxygen concentration of at least $7-8 \mathrm{mg} \cdot \mathrm{L}^{-1}$. Then, the decrease of oxygen content due to the microorganism activity was monitored. Oxygen probe of the multiparameter meter by HACH was used to determine the concentration of dissolved oxygen, which was recorded in 30 second intervals.

Using respirometric measurements, the effect of selected antibiotics on endogenous and exogenous respiration rate of activated sludge microorganisms was monitored. In exogenous respirometric tests, a sodium acetate solution was used as a source of exogenous substrate, while the final concentration of substrate in the vessel was $5.20 \mathrm{mg} \cdot \mathrm{L}^{-1}$. Syringes were used to inject the exogenous substrate solution as well as the antibiotic solution. Complete apparatus is shown in Fig. 1.



Fig. 1. Apparatus used for respirometric measurements.

Nine respirometric tests for each tested antibiotic (5 endogenous and 4 exogenous respirometric tests) were performed. First, the effect of the selected antibiotic on endogenous respiration rate was determined. The first endogenous test was performed with activated sludge without the addition of antibiotics (control test, twice repeated). The other three tests were performed with the addition of different concentrations of the studied antibiotics. Exogenous respirometric measurements were done in the same way. The first measurement (control test) was performed with activated sludge to which $5.20 \mathrm{mg} \cdot \mathrm{L}^{-1}$ of external substrate were added. In the following three measurements, the tested antibiotics were added respectively. Concentrations of antibiotics added to the respirometric cell during the respiratory tests were as follows: for SMX: 0.142; 0.425; $1.42 \mathrm{mg} \cdot \mathrm{L}^{-1}$, for SP: $0.134 ; 0.403 ; 1.34 \mathrm{mg} \cdot \mathrm{L}^{-1}$, and for CPX: 0.104; 0.313; $1.04 \mathrm{mg} \cdot \mathrm{L}^{-1}$.

To evaluate respiration rates, time course of dissolved oxygen concentration from the measured values for each respirometric measurement was plotted.

In endogenous respirometric measurements, respiration rate was calculated from the linear part of the dependence of the oxygen concentration decrease with time. The volumetric respiration rate, $r_{v, o x}\left(\mathrm{mg}_{\mathrm{O}_{2}} \cdot \mathrm{L}^{-1} \cdot \mathrm{h}^{-1}\right)$, was calculated according to the equation:

$$
-r_{v, 0 x}=\mathrm{d} c\left(\mathrm{O}_{2}\right) / \mathrm{d} t
$$

Specific respiration rate, $r_{x, o x}\left(\mathrm{mg}_{\mathrm{O}_{2}} \cdot \mathrm{g}^{-1} \cdot \mathrm{h}^{-1}\right)$, was then calculated from the volumetric respiration rate according to the equation:

$$
r_{x, o x}=r_{v, o x} / X_{c}
$$

After calculating the specific respiration rate, the percentage efficacy of the inhibitory effect, $I(\%)$, of the selected antibiotic on endogenous respirometry 
was determined by comparing the specific respiration rates measured in the absence, $r_{x, o x(c o n t r o l)}$, and in the presence of the monitored antibiotic, $r_{x, \text { ox (sample })}$. The percentage inhibition efficiency was calculated according to the equation:

$$
I=\left(r_{x, \text { ox (control })}-r_{x, \text { ox (sample })} / r_{x, \text { ox (control })}\right) \times 100
$$

When evaluating exogenous respiration rates, two breaking points were identified on the respirogram. The first is due to the exogenous substrate dose, which increased the endogenous oxygen consumption, $r_{x, o x, e n}$, by the substrate (exogenous) consumption for added substrate oxidation, $r_{x, o x}$. The second point marked the second endogenous phase after the exogenous substrate consumption. The searched phases can be seen in Fig. 2. From the linear section of the endogenous phase, endogenous respiration rate, $r_{x, o x, e n}$, was calculated according to Eq. 2. From the linear section of total respirometry, the total respiration rate, $r_{x, o x, t .}$, was determined Subsequently, the exogenous respiration rate, $r_{x, 0 x}$, was calculated from the equation:

$$
r_{x, o x}=r_{x, o x, e n}-r_{x, o x, t}
$$

Then, the percentage efficacy of the inhibitory effect of the selected antibiotic was determined by comparing the specific respiration rates measured in the absence, $r_{x, o x, e x(c o n t r o l)}$, and in the presence of the monitored antibiotic, $r_{x, o x, e x(s a m p l e)}$. The percentage inhibition efficiency was determined according to the equation:

$$
I=\left(r_{x, o x, e x(\text { control })}-r_{x, o x, e x(\text { sample })} / r_{x, o x, e x(\text { control })}\right) \times 100
$$

From the known substrate concentration in the respirometer after its injection, $S$ (calculated from the known concentration of substrate stock solution, respirometer volume and substrate injection

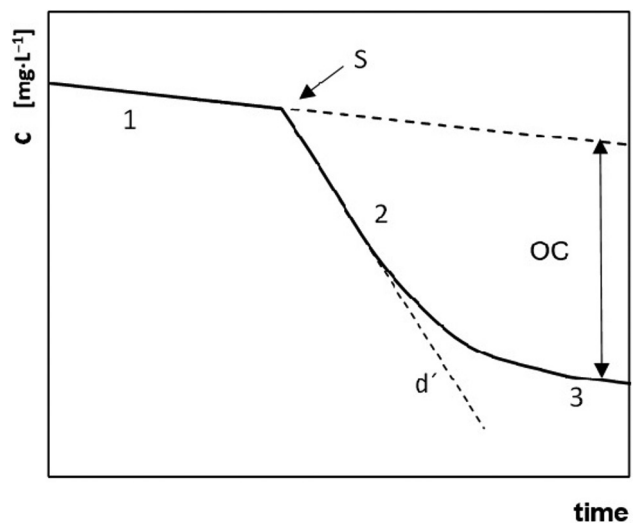

Fig. 2. Typical respirogram: 1 and $3-$ endogenous respiration, 2 - total respiration (endogenous + substrate/exogenous), $\mathrm{S}-$ substrate dose, $\mathrm{OC}-\mathrm{O}_{2}$ consumption for substrate dose, $\mathrm{d}^{\prime}-$ tangent to the total respiration curve at the injection point. volume), and the known $O C$ value $\left(\mathrm{O}_{2}\right.$ consumption for substrate dose), biomass production coefficient $Y\left(\mathrm{mg}_{\text {CODbiomass }} \cdot \mathrm{mg}_{\text {CODsubstrate }}{ }^{-1}\right)$ can be determined according to Fig. 2.

$$
Y=1-(O C / S)
$$

Substrate removal rate, $r_{x}\left(\mathrm{mg}_{\mathrm{COD}} \cdot \mathrm{g}^{-1} \cdot \mathrm{h}^{-1}\right)$, is calculated from the values of substrate respiration rate, $r_{x, o x}$, and biomass production coefficient, $Y$, according to the equation:

$$
r_{x}=r_{x, o x} /(1-Y)
$$

The first two measurements were performed in the absence of the monitored antibiotic, and the average of these two measurements were considered in the results. The other three measurements were performed with the sequential addition of $1 \mathrm{~mL}, 3 \mathrm{~mL}$, and $10 \mathrm{~mL}$ of stock solution. The respective values of antibiotic concentrations in the respirometer after their injection are given in Tab. 2. Due to its low value, antibiotic concentration in the COD indicator was neglected as a possible source of exogenous substrate. After calculating the substrate removal rate, as in the case of exogenous respiration rates, the percentage inhibitory effect of selected antibiotics was determined according to:

$$
I=\left(r_{x(\text { control })}-r_{x(\text { sample })} / r_{x(\text { control })}\right) \times 100
$$

\section{Results and discussion}

\section{Endogenous respirometric measurements}

To monitor the effect of the selected antibiotics on the endogenous respiration rate of activated sludge, four endogenous respirometric measurements for each antibiotic were performed. Each measurement lasted for 15 minutes. Dissolved oxygen concentration values were recorded at 30 second intervals. The monitored antibiotic injected into the respirometric vessel at the $90^{\text {th }}$ second of the measurement. For all respirometric measurements, a new mixture of activated sludge aerated to oxygen concentration of at least $7-8 \mathrm{mg} \cdot \mathrm{L}^{-1}$ was used. Individual concentrations of activated sludge and antibiotics used in the measurements are given in Tab. 2.

After performing individual measurements, the time course of the dissolved oxygen concentration decrease was plotted from the measured data. As an example, the time course of dissolved oxygen for CPX is shown below, along with the linear squares equations evaluated by the least squares method (Fig. 3). Graphical dependencies for other antibiotics were evaluated in the same way.

It can be seen from the graph that the rate of dissolved oxygen decrease in the respirometer changes 
Tab. 2. Concentrations of activated sludge and antibiotics used in the respirometric measurements.

\begin{tabular}{lcccc}
\hline No. of measurement & $\begin{array}{c}\text { Concentration of AS } \\
{\left[\mathbf{g} \cdot \mathbf{L}^{-1}\right]}\end{array}$ & $\begin{array}{c}\text { Volume of added ATB } \\
{[\mathbf{m L}]}\end{array}$ & $\begin{array}{c}\text { Concentration } \\
\text { of ATB in cell } \\
{\left[\mathbf{m g} \cdot \mathbf{L}^{-1}\right]}\end{array}$ \\
\hline $\mathbf{S M X}$ & 1 & 0.850 & 0 & 0.000 \\
& 2 & 0.850 & 1 & 0.142 \\
& 3 & 0.850 & 3 & 0.425 \\
$\mathbf{S P}$ & 4 & 0.850 & 10 & 1.42 \\
\hline & 1 & 1.40 & 0 & 0.000 \\
& 3 & 1.40 & 1 & 0.134 \\
& 4 & 1.40 & 3 & 0.403 \\
& 1 & 1.40 & 10 & 1.34 \\
\hline
\end{tabular}

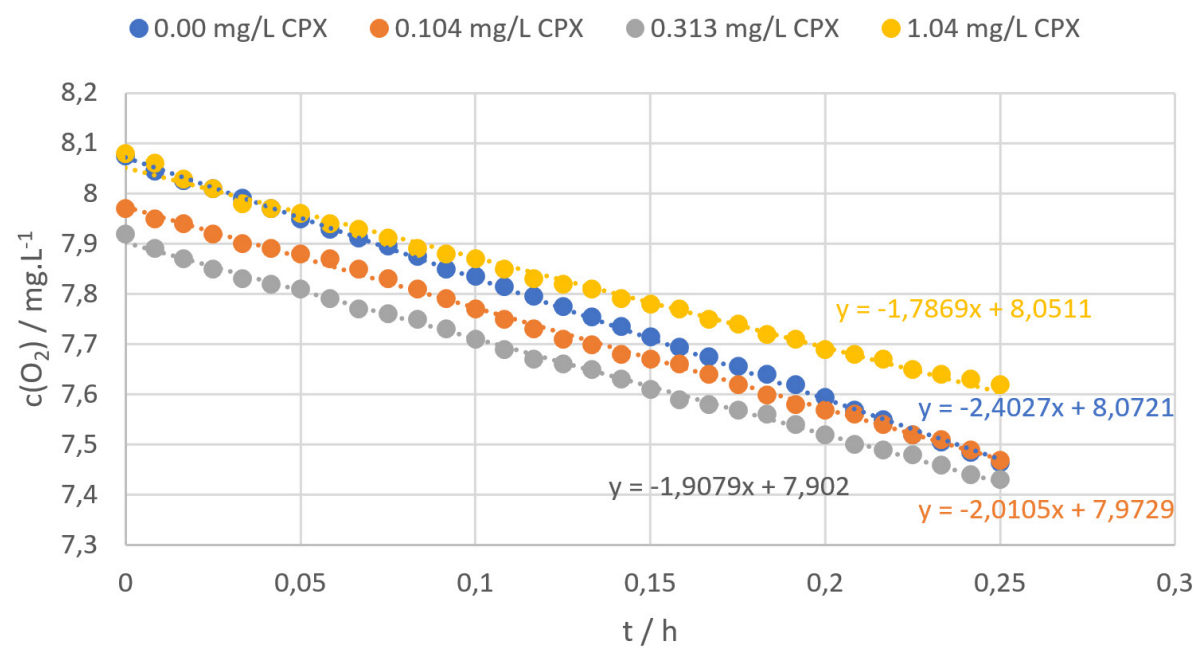

Fig. 3. Time course of dissolved oxygen concentration for CPX.

Tab. 3. Endogenous respiration rates of activated sludge without and in the presence of antibiotics.

\begin{tabular}{|c|c|c|c|c|c|}
\hline & $\begin{array}{c}\text { Volume of added } \\
\qquad \text { ATB } \\
{[\mathrm{mL}]}\end{array}$ & $\begin{array}{c}\text { Concentration } \\
\text { of ATB in cell } \\
{\left[\mathrm{mg} \cdot \mathrm{L}^{-1}\right]} \\
\end{array}$ & $\begin{array}{c}\text { Volumetric } \\
\text { respiration rate } \\
{\left[\mathrm{mg} \cdot \mathrm{L}^{-1} \cdot \mathbf{h}^{-1}\right]}\end{array}$ & $\begin{array}{c}\text { Specific } \\
\text { respiration rate } \\
{\left[\mathrm{mg} \cdot \mathrm{g}^{-1} \cdot \mathrm{h}^{-1}\right]} \\
\end{array}$ & $\begin{array}{c}\text { Inhibition } \\
{[\%]}\end{array}$ \\
\hline \multirow{4}{*}{ SMX } & 0 & 0.000 & 1.77 & 2.09 & - \\
\hline & 1 & 0.142 & 1.55 & 1.83 & 12.5 \\
\hline & 3 & 0.425 & 1.50 & 1.77 & 15.4 \\
\hline & 10 & 1.42 & 1.49 & 1.76 & 15.8 \\
\hline \multirow{4}{*}{ SP } & 0 & 0.000 & 3.55 & 2.53 & - \\
\hline & 1 & 0.134 & 3.03 & 2.16 & 14.6 \\
\hline & 3 & 0.403 & 2.84 & 2.03 & 19.9 \\
\hline & 10 & 1.34 & 2.42 & 1.73 & 31.9 \\
\hline \multirow{4}{*}{ CPX } & 0 & 0.000 & 2.40 & 3.59 & - \\
\hline & 1 & 0.104 & 2.01 & 3.00 & 16.3 \\
\hline & 3 & 0.313 & 1.91 & 2.85 & 20.6 \\
\hline & 10 & 1.04 & 1.79 & 2.67 & 25.6 \\
\hline
\end{tabular}


with the gradual addition of antibiotics - this applies for each monitored antibiotic. This change in the rate of oxygen consumption by the activated sludge microorganisms is also reflected in the slopeintercept form of a line. The values of the slopes differ for each measurement and the decrease in their values is directly proportional to the amount of added antibiotic.

Volumetric endogenous respiration rates were calculated from the slopes of linear squares equations evaluated by the least squares method. These rates were then converted according to Eq. 2 to specific endogenous respiration rate related to the concentration of activated sludge in the respirometer. All calculated values of endogenous respiration rates are given in Tab. 3 .

Based on the calculated values of respiration rates, gradual addition of the antibiotic decreases the volume as well as the specific endogenous respiration rates of activated sludge. The same trend applies to each of the monitored antibiotic. In such a case, inhibitory effect of the monitored antibiotics on the endogenous activity of activated sludge microorganisms can be determined. The cause of the inhibitory effect of antibiotics in general may be insufficient adaptation of microorganisms to their presence. However, considering that the respirometric tests were performed using sludge adapted to the presence of certain concentrations of antibiotics in real wastewater, the observed inhibitory phenomenon can also indicate the toxic effect of selected antibiotics and their concentrations on the population of activated sludge microorganisms.

To express the degree of inhibitory effect of individual antibiotics on the respirometric activity of activated sludge, percentage of inhibition was determined based on the difference between the specific respiration rate measured in the absence of the monitored antibiotic and in its presence in the given concentrations (Eq. 3). Results of the percentage inhibition rate are shown in Tab. 3 and as graphical dependences of the degree of inhibition on the concentration of each antibiotic in Fig. 4. The results show that sulfamethoxazole (SMX) has the least inhibitory effect on activated sludge, with the inhibition rate ranging from $12.5 \%$ to $15.8 \%$ within its concentration range of $0.142-1.42 \mathrm{mg} \cdot \mathrm{L}^{-1}$. When $1.34 \mathrm{mg} \cdot \mathrm{L}^{-1}$ of $\mathrm{SP}$ was used, the highest rate of inhibition, approximately $32 \%$, was recorded. For CPX, the inhibition rate ranges from $16.3 \%$ to $25.6 \%$ within its concentration range of $0.104-10.4 \mathrm{mg} \cdot \mathrm{L}^{-1}$.

\section{Exogenous respirometric measurements}

To determine exogenous respiration rates of activated sludge, four exogenous respirometric measurements for each antibiotic were performed: the first exogenous test was performed with an addition of external substrate to the respirometric cell without antibiotics; subsequently, three more tests were performed with the addition of external substrate and of different concentrations of the individual antibiotics. One measurement lasted 30 to 35 minutes, depending on the rate of consumption of the added exogenous substrate (in our case sodium acetate). Dissolved oxygen concentration values were recorded at 30 second intervals. For these measurements, the exogenous substrate and antibiotic were injected into the respirometric vessel at the $5^{\text {th }}$ minute of the measurement.

For all measurements with a given antibiotic, the same mixture of activated sludge and the same amount of external substrate were used. In these measurements, sodium acetate was used as exogenous substrate in a volume of $2 \mathrm{~mL}$, which represents the concentration of the exogenous substrate $\mathrm{COD}=5.20 \mathrm{mg} \cdot \mathrm{L}^{-1}$. After each measurement, new sludge mixture was aerated to perform

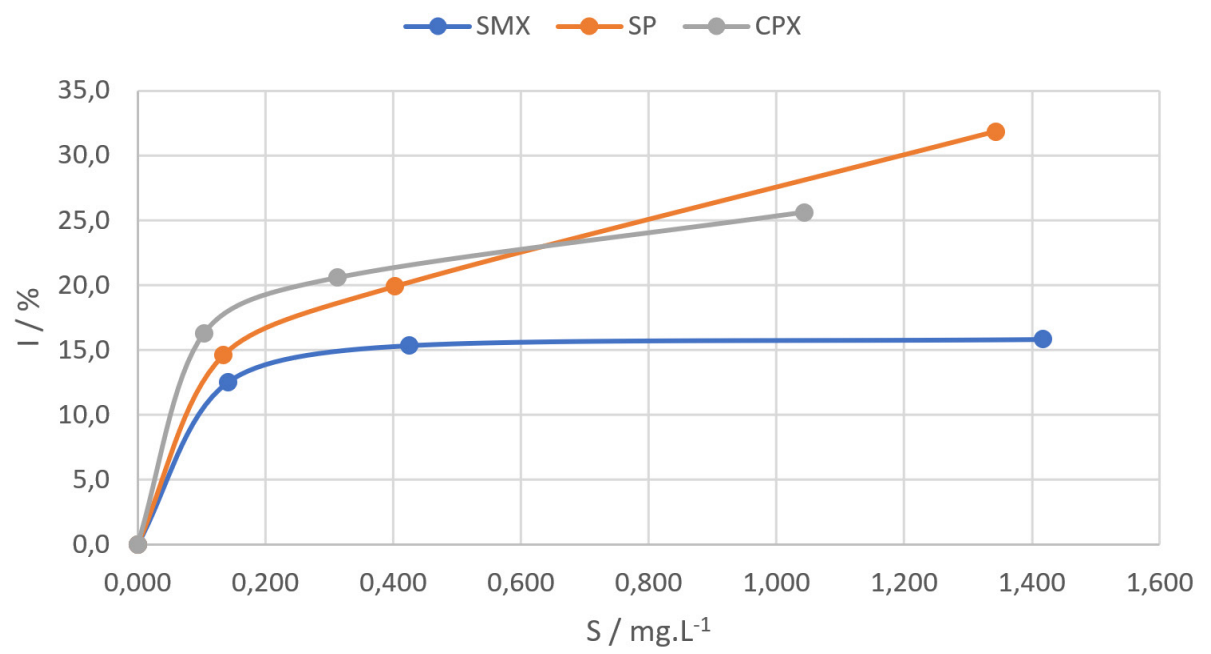

Fig. 4. Degree of inhibition as a function of the amount of monitored antibiotic. 
the next measurement. Individual concentrations of activated sludge and exogenous substrate for measurements with a given antibiotic are summarized in Tab. 4.

The first measurement in a series of measurements was performed in the absence of antibiotics, only with the addition of exogenous substrate. Subsequently, three measurements were performed with the addition of the same amount of exogenous substrate and gradual addition of antibiotics in the volume of $1 \mathrm{~mL}, 3 \mathrm{~mL}$, and $10 \mathrm{~mL}$ of stock solution. The respective antibiotic concentrations in the respirometer after their injection are given in Tab. 4. Due to its low value, antibiotic concentration in the COD indicator was neglected as a possible source of external substrate.

After the measurements, time course of the decrease in the dissolved oxygen concentration was plotted from the measured data and three phases were identified. The first is the endogenous respiration phase, when no external substrate was added to the system. The second is the total respiration (endogenous + substrate/exogenous) phase, which occurred after the injection of exogenous substrate and the endogenous respiration rate was also increased by the exogenous (substrate) respiration rate. Lastly, the third endogenous phase, which occurred after the consumption of the added exogenous substrate, was identified. As an example, the time course of dissolved oxygen concentration for $\mathrm{SP}$ is shown below, along with the linear squares equations evaluated by the least squares method (Fig. 5). Time courses of dissolved oxygen concentration for other antibiotics were evaluated in the same way.
Specific exogenous respiration rates were calculated using Eq. 4 as the difference between the total respiration rate, calculated from the ratio of the slope of the line of the total respiration phase and the activated sludge concentration in the respirometer, and the endogenous respiration rate, calculated as the ratio of the slope of the line of the first endogenous phase and the activated sludge in the respirometer. From these specific exogenous respiration rates, substrate removal rates were calculated according to Eq. 6 . The value of dissolved oxygen consumption for exogenous substrate oxidation, OC, was calculated as the difference of oxygen concentrations of the intercept of the first and second endogenous phase. All calculated values of specific exogenous respiration rates and substrate removal rates for individual measurements are given in Tab. 5 .

Based on the resulting values of respiration rates and substrate removal rates, it can be concluded that, as with endogenous measurements, exogenous respiration rates and substrate removal rates decrease with gradual antibiotic addition. The same trend can be observed for each monitored antibiotic. In this case, the inhibitory effect of the monitored antibiotics on the exogenous respiration rates of activated sludge microorganisms and the rate of substrate removal can be determined. As in the case of endogenous respiration rates, the inhibitory effect observed in this case may indicate toxic effect of the monitored antibiotics on activated sludge microorganisms as significant inhibitory effect is observed despite the adaptation of the activated sludge mixture to the presence of antibiotics in nano- to micro-concentrations.

Tab. 4. Concentrations of activated sludge, external substrate, and antibiotics used in the respirometric measurements.

\begin{tabular}{|c|c|c|c|c|c|}
\hline & No. of measurement & $\begin{array}{c}\text { Concentration } \\
\text { of AS } \\
{\left[\mathrm{g} \cdot \mathrm{L}^{-1}\right]}\end{array}$ & $\begin{array}{c}\text { Concentration } \\
\text { of exogenous substrate } \\
{\left[\mathrm{mg} \cdot \mathrm{L}^{-1}\right]}\end{array}$ & $\begin{array}{c}\text { Volume } \\
\text { of added ATB } \\
{[\mathrm{mL}]}\end{array}$ & $\begin{array}{c}\text { Concentration } \\
\text { of ATB in cell } \\
{\left[\mathrm{mg} . \mathrm{L}^{-1}\right]}\end{array}$ \\
\hline \multirow{4}{*}{ SMX } & 1 & 0.850 & 5.32 & 0 & 0.000 \\
\hline & 2 & 0.850 & 5.32 & 1 & 0.142 \\
\hline & 3 & 0.850 & 5.32 & 3 & 0.425 \\
\hline & 4 & 0.850 & 5.32 & 10 & 1.42 \\
\hline \multirow{4}{*}{ SP } & 1 & 1.40 & 5.32 & 0 & 0.000 \\
\hline & 2 & 1.40 & 5.32 & 1 & 0.134 \\
\hline & 3 & 1.40 & 5.32 & 3 & 0.403 \\
\hline & 4 & 1.40 & 5.32 & 10 & 1.34 \\
\hline \multirow{4}{*}{ CPX } & 1 & 0.670 & 5.32 & 0 & 0.000 \\
\hline & 2 & 0.670 & 5.32 & 1 & 0.104 \\
\hline & 3 & 0.670 & 5.32 & 3 & 0.313 \\
\hline & 4 & 0.670 & 5.32 & 10 & 1.04 \\
\hline
\end{tabular}



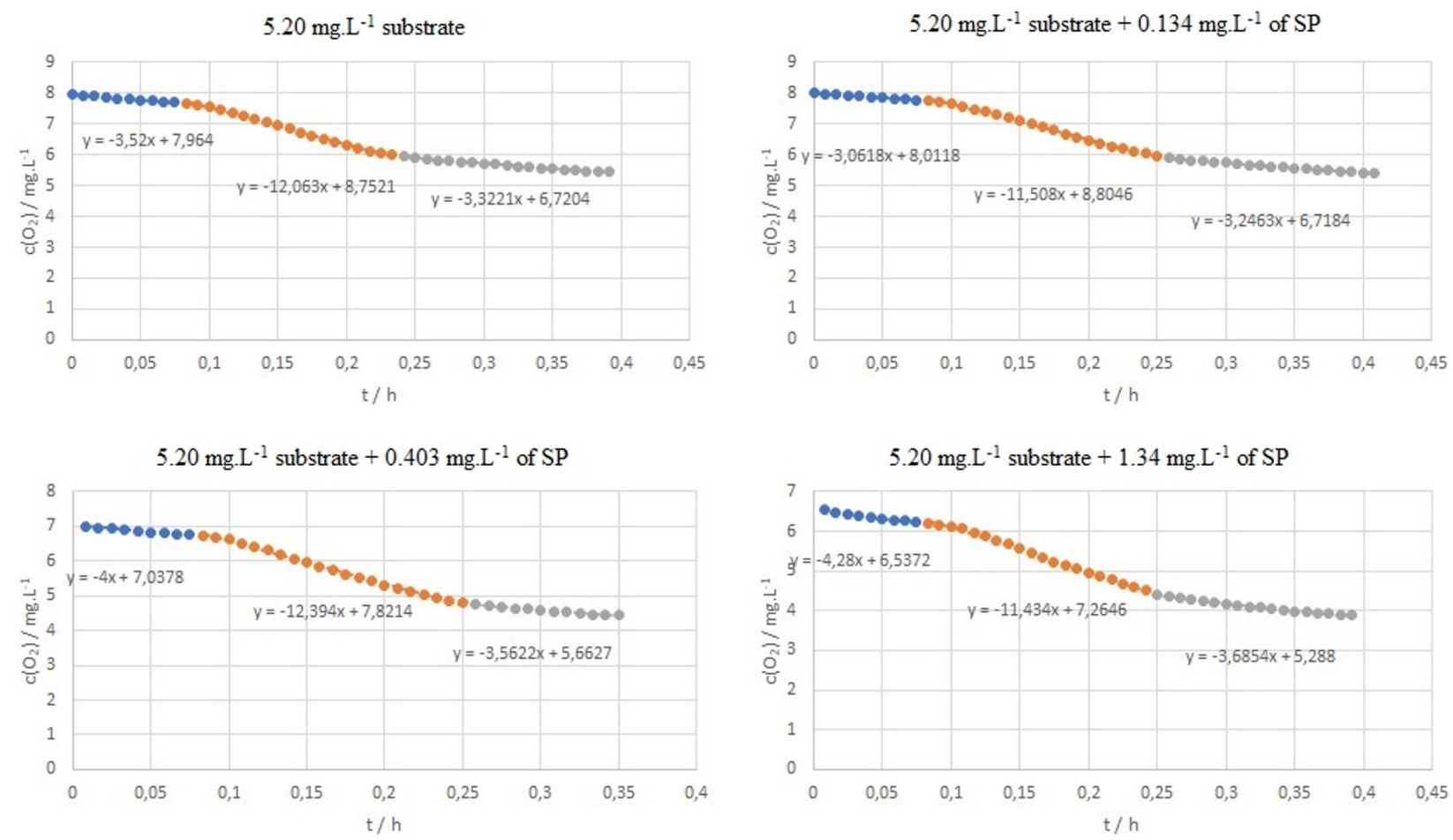

Fig. 5. Time course of dissolved oxygen concentration for antibiotic SP.

Tab. 5. Exogenous respiration rates of AS and substrate removal rates measured in the absence and in the presence of antibiotics, and inhibition values for individual antibiotics and their volumes.

\begin{tabular}{|c|c|c|c|c|c|c|}
\hline & $\begin{array}{c}\text { Volume } \\
\text { of added ATB } \\
{[\mathrm{mL}]}\end{array}$ & $\begin{array}{c}\text { Concentration } \\
\text { of ATB in cell } \\
{\left[\mathrm{mg} \cdot \mathrm{L}^{-1}\right]}\end{array}$ & $\begin{array}{c}\text { Exogenous } \\
\text { respiration rate } \\
{\left[\mathrm{mg}_{\mathrm{o}_{2}} \cdot \mathrm{g}^{-1} \cdot \mathrm{h}^{-1}\right]}\end{array}$ & $\begin{array}{c}\text { Substrate } \\
\text { removal rate } \\
{\left[\mathrm{mg}_{\mathrm{COD}} \cdot \mathrm{g}^{-1} \cdot \mathbf{h}^{-1}\right]}\end{array}$ & $\begin{array}{c}\text { Inhibition } \\
\text { of respiration } \\
\text { rate } \\
{[\%]}\end{array}$ & $\begin{array}{c}\text { Inhibition } \\
\text { of substrate } \\
\text { removal rate } \\
{[\%]}\end{array}$ \\
\hline \multirow{4}{*}{ SMX } & 0 & 0.000 & 5.06 & 24.0 & - & - \\
\hline & 1 & 0.142 & 4.57 & 19.5 & 9.67 & 19.1 \\
\hline & 3 & 0.425 & 4.26 & 19.4 & 15.7 & 19.3 \\
\hline & 10 & 1.42 & 4.25 & 17.4 & 16.0 & 27.7 \\
\hline \multirow{4}{*}{ SP } & 0 & 0.000 & 6.10 & 26.1 & - & - \\
\hline & 1 & 0.134 & 6.03 & 24.8 & 1.13 & 4.9 \\
\hline & 3 & 0.403 & 6.00 & 23.2 & 1.74 & 11.1 \\
\hline & 10 & 1.34 & 5.11 & 21.8 & 16.3 & 16.6 \\
\hline \multirow{4}{*}{ CPX } & 0 & 0.000 & 9.62 & 42.9 & - & - \\
\hline & 1 & 0.104 & 9.02 & 41.0 & 6.30 & 4.55 \\
\hline & 3 & 0.313 & 8.55 & 36.8 & 11.1 & 14.3 \\
\hline & 10 & 1.04 & 7.40 & 30.9 & 23.1 & 28.0 \\
\hline
\end{tabular}

To express the degree of inhibitory effect of individual antibiotics on the respirometric activity of activated sludge, the percentage of inhibition was determined based on the difference between specific exogenous respiration rates and substrate removal rates measured in the absence and in the presence of given amounts of the selected antibiotics using Eq. 5 and Eq. 8. Results of the percentage of inhibition degree are shown in Tab. 5 and dependences of the degree of inhibition on the concentration of the test substance plotted for each antibiotic can be seen in Figs. 6 and 7.

The results show that the degree of respiration rate inhibition for SMX concentration range $0.142-1.42 \mathrm{mg} \cdot \mathrm{L}^{-1}$ is between $9.67 \%$ and $16.0 \%$. The degree of inhibition of the substrate removal rate is slightly higher (19.1-27.7\%).

From the results of measurements with antibiotic SP $\left(0.134-1.34 \mathrm{mg} \cdot \mathrm{L}^{-1}\right)$, it can be observed that the inhibition of respiration rate is relatively low 


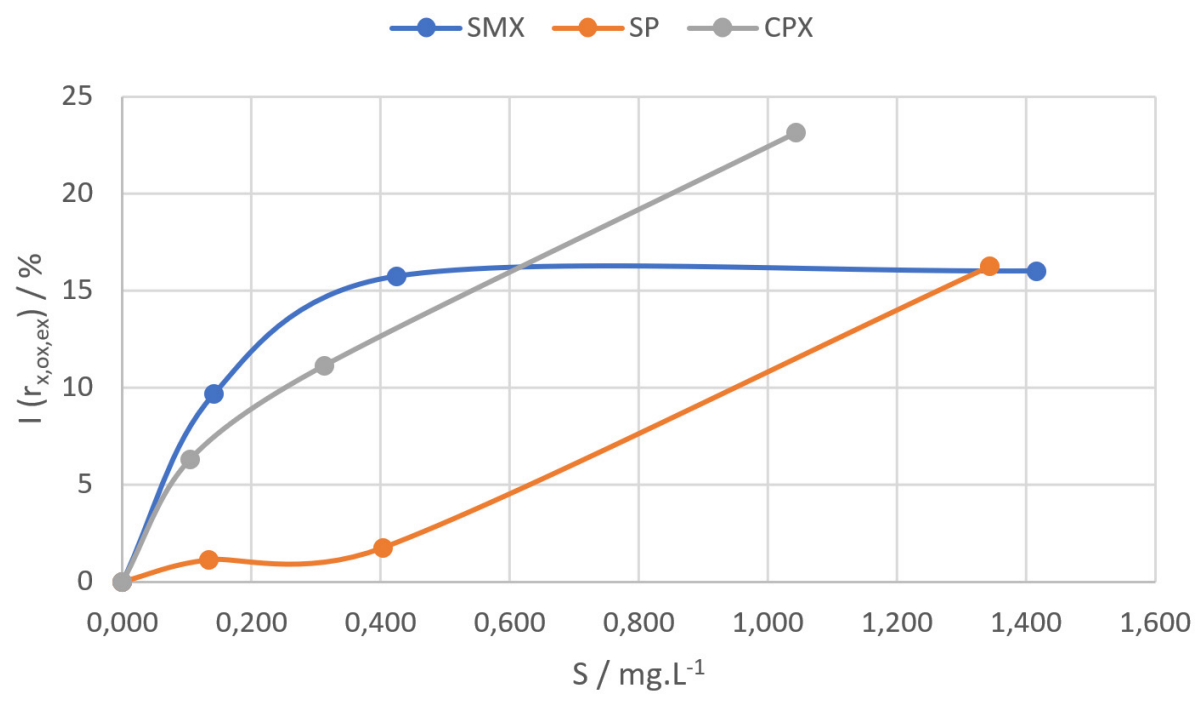

Fig. 6. Degree of exogenous respiration rate inhibition depending on the amount of monitored antibiotic.

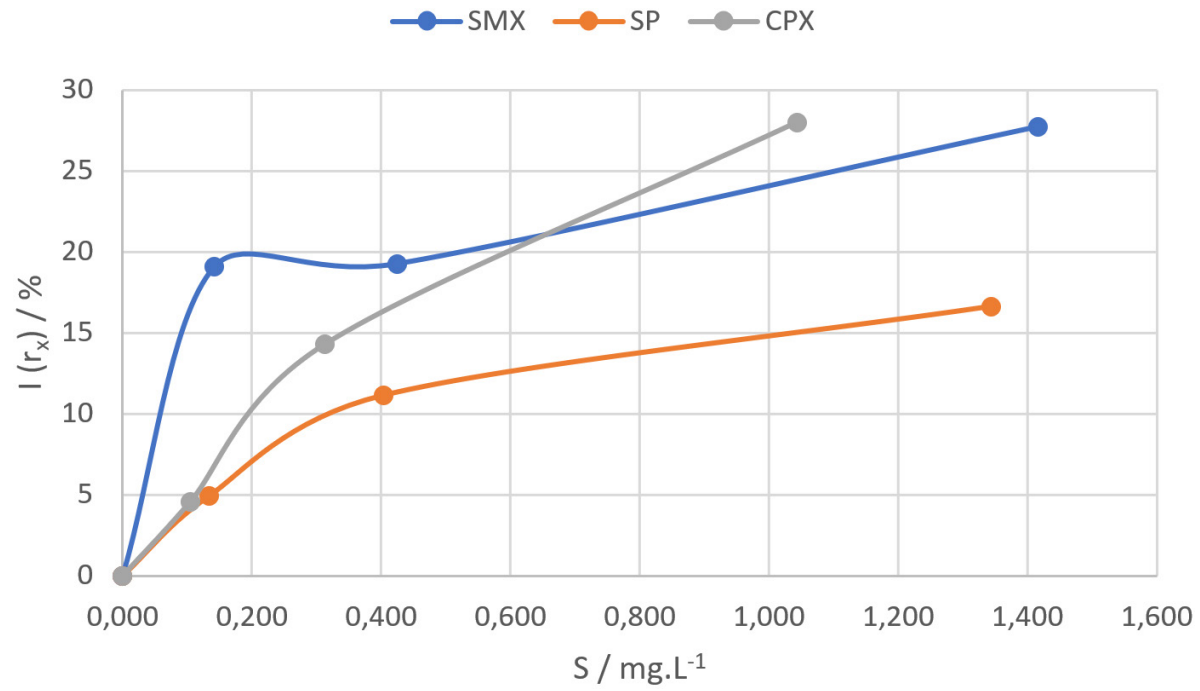

Fig. 7. Degree of substrate removal rate inhibition depending on the amount of monitored antibiotic.

at lower concentrations ( $1.13 \%$ and $1.74 \%)$. At the highest concentration monitored, the degree of inhibition of respiration rate increased to $16.3 \%$ while the highest inhibitory effect of substrate removal rate, $16.6 \%$, was observed for the measurement with the addition of $1.34 \mathrm{mg} \cdot \mathrm{L}^{-1}$ of SP. For other SP concentrations, the inhibitory effect ranged from 4.94 to $11.1 \%$.

For antibiotic CPX, inhibition of the respiration rate in the range from $6.30-23.1 \%$ and the substrate removal rate of 4.55-28.0\% was determined for concentration range from 0.104 to $1.04 \mathrm{mg} \cdot \mathrm{L}^{-1}$. Respirometric experiments and their evaluation confirmed the expected influence of antibiotics on the activity of AS microorganisms and thus on the activation process itself.

Most recent literature studies focused on respirometry application dealt with acute (i.e. short-term) toxicity (Aguilar et al., 2020; Cristóvão et al., 2016; Ortiz de García et al., 2014; Tominaga et al., 2018): as an example, Faria et al. (2021) studied toxicity cycles lasting $8 \mathrm{~h}$ using respirometry. However, the study by Vasiliadou et al. (2018) investigated also long-term toxicity effects, giving useful insights on possible issues related to long-term reduction in sludge activity observed in full-scale WWTP operations. In this publication, the authors focused on the evaluation of the three pharmaceutical compounds (caffeine, sulfamethoxazole, and carbamazepine) inhibition on two cultures of microbial consortia enriched from wastewater aerobic activated sludge. One of them was acclimatized to pharmaceuticals and the other was non-acclimated as control bioassay. The inhibitory effect on these cultures was assessed by respirometric tests through the oxygen uptake rate as an indicator of their capacity to 
degrade a readily available carbon source. Higher values of toxicity and inhibition of pharmaceutical compounds were observed for the control culture compared to the acclimated one. To evaluate the inhibitory effect of SMX on acclimatized culture, five respiormetric experiments were performed using: 100, 200, 300, 600 and $1000 \mu \mathrm{g}(\mathrm{SMX}) \cdot \mathrm{L}^{-1}$. The results indicate that the inhibitory effect of this substance also increases with the increasing SMX concentration. At the SMX concentration of $1000 \mu \mathrm{g} \cdot \mathrm{L}^{-1}$, the inhibition of $52 \%$ for the acclimated mixed culture was measured. For concentrations of 200 and $600 \mu \mathrm{g} \cdot \mathrm{L}^{-1}$, SMX inhibitions were approximately $1 \%$ and $44 \%$, respectively. Respirometric tests for control mixed culture were performed at SMX concentration of $200 \mu \mathrm{g} \cdot \mathrm{L}^{-1}$ (30\% inhibition) and $600 \mu \mathrm{g} \cdot \mathrm{L}^{-1}$ (70 \% inhibition). In case of the control culture, the inhibitory effects were significantly increased compared to the acclimated one. These results indicated that the acclimation of mixed culture to pharmaceuticals promoted higher resistance to the toxic and inhibitory effects of pharmaceutical compounds. Thus, the control mixed culture was more sensitive than acclimated culture because the acclimated mixture of microorganisms was adapted to the toxic/inhibitory environment of pharmaceuticals. This is in agreement with the results reported in literature suggesting that microbial communities exposed to various loads of pharmaceuticals may develop specific adaptations and may built up stronger resistance to pharmaceuticals' effects (i.e. antibiotics) (Chonova et al., 2016). Our results were compared with those with adapted sludge as the sludge in our paper subjected to respirometric experiments was also adapted to pharmaceuticals. In case of using $0.425 \mathrm{mg}(\mathrm{SMX}) \cdot \mathrm{L}^{-1}$, inhibition of approximately $16 \%$ was observed while $44 \%$ were reported for a concentration of $600 \mu \mathrm{g} \cdot \mathrm{L}^{-1}$ in the study. Although the concentrations are not identical, they show some degree of sludge inhibition. As such, it is a confirmation that this issue needs to be further addressed.

In further studies, inhibition of nitrifying bacteria activity is addressed (Xing and Jin, 2018; Faria et al., 2021). The study by Faria et al. (2021) deals with the determination of the inhibitory effect in the AS nitrification process. The tests were conducted by comparing respiration rates with effluent containing ammonia nitrogen and nitrite nitrogen called "reference" and batches containing toxic effluent doped with different concentrations of amoxicillin (AMX) called "process". The addition of $20 \mathrm{mg} \cdot \mathrm{L}^{-1}$ caused a small decrease in AOB and NOB populations, which resulted in a $35 \%$ reduction in the nitrification process efficiency. For tests with the
AMX concentration of $100 \mathrm{mg} \cdot \mathrm{L}^{-1}$, the inhibition effect was $91 \%$ for NOB and $56 \%$ for AOB. The authors therefore concluded that the population of NOB was the most sensitive to AMX toxicity. Although AMX negatively influences nitrification at higher concentrations than found in wastewater, it highlights the need for technologies to remove this antibiotic from wastewater not only to ensure the nitrification process operation but mainly to protect aquatic organisms and human health.

Respirometric tests were shown to be useful in evaluating the toxicity of a wide spectrum of contaminants of emerging concern (CECs), such as pharmaceuticals, personal care products (PCPs), heavy metals, or nanoparticles.

\section{Conclusion}

In the experimental part of this work, several respirometric measurements were performed to determine the effect of three selected antibiotics, sulfamethoxazole (SMX), sulfapyridine (SP) and ciprofloxacin (CPX), on the activity of activated sludge (AS) microorganisms. The measurements were performed at three different concentrations of each of these antibiotics. Adapted sludge from WWTP Bratislava - Devínska Nová Ves was used in the measurements. First, endogenous respirometric measurements were performed to determine the effect of antibiotics on the endogenous activity of AS microorganisms. For all antibiotics used, their inhibitory effect on the endogenous respiration rate of AS was monitored. Percentage inhibition for these measurements ranged from $12.5 \%$ to $31.9 \%$. The highest degree of inhibition was achieved in the presence of SP $\left(1.34 \mathrm{mg} \cdot \mathrm{L}^{-1}\right)$ whereas SMX $\left(0.142 \mathrm{mg} \cdot \mathrm{L}^{-1}\right)$ had the lowest inhibitory effect. In the second part of the experiments, exogenous respirometric measurements were performed using sodium acetate as an exogenous source of substrate. In this case, inhibitory effect was also observed for all three antibiotics studied. The degree of inhibition in these measurements was from $1.13 \%$ (for $\mathrm{SP}$ concentration of $0.134 \mathrm{mg} \cdot \mathrm{L}^{-1}$ ) to $23.1 \%$ (for CPX concentration of $1.04 \mathrm{mg} \cdot \mathrm{L}^{-1}$ ) for exogenous respiration rates. For substrate removal rates, the inhibitory effect was between $4.55 \%$ (for CPX concentration of $0.104 \mathrm{mg} \cdot \mathrm{L}^{-1}$ ) and $28.0 \%$ (for CPX concentration of $1.04 \mathrm{mg} \cdot \mathrm{L}^{-1}$ ). The highest degree of inhibition was observed at the highest CPX concentration $\left(1.04 \mathrm{mg} \cdot \mathrm{L}^{-1}\right)$. The respirometric measurements and their evaluation confirmed the expected influence of antibiotics on the AS microorganisms' activity, and thus on the activation process itself. Inhibitory effects were observed in all respirometric measurements for 
each antibiotic monitored, which may indicate a deterioration in the ability of the AS microorganisms to remove dissolved forms of contaminants from wastewater (if substances such as pharmaceuticals or drugs are present in wastewater). It should be noted that the values of antibiotic concentrations in these measurements were significantly higher than real antibiotic concentrations in wastewater. However, due to the relatively high values of inhibition measured at our chosen antibiotic concentrations, a certain degree of inhibition can be assumed even at lower antibiotic concentrations (however, wastewater contains hundreds of pharmaceutical substances the total concentration of which is often in tens of thousands, sometimes in the hundreds of thousands, nanograms per liter) such as e.g. pharmaceutical concentrations present in wastewater. To clearly confirm these results, it is necessary to further pursue this issue in future.

\section{Acknowledgement}

This work was supported by the Slovak Research and De velopment Agency under the contract No. APVV-0119-17.

\section{References}

Aguilar MI, Lloréns M, Fernández-Garrido JM, PérezMarín AB, Ortuño JF, Meseguer VF (2020) Int. J. Environ. Sci. Technol. 17: 3111-3118.

Aydin S, Ince B, Ince O (2015) Water Res. 83: 337-344.

Aydin S, Ince B, Ince O (2016) Appl. Microbiol. Biotechnol. 100: 6491-6499.

Chonova T, Keck F, Labanowski J, Montuelle B, Rimet F, Bouchez A (2016) Sci. Total. Environ. 542: 965-975.

Cristóvão RO, Pinto VMS, Martins RJE, Loureiro JM, Boaventura RAR (2016) J. Clean. Prod. 127: 343-351.
Dai G, Wang B, Huang J, Dong R, Deng S, Yu G (2015) Chemosphere 119: 1033-1039.

Faria JK, Conceição ACS, Kohatsu MY, Okamoto AB (2021) Curr. Microbiol. 78: 167-178.

Foladori P, Bruni L, Tamburini S (2014) J. Hazard. Mater. 280: 758-766.

Gago-Ferrero P, Gros M, Ahrens L, Wiberg K (2017) Sci. Total. Environ. 601-602: 1289-1297.

Golovko O, Kumar V, Fedorova G, Randak T, Grabic R (2014) Environ. Sci. Pollut. Res. 21: 7578-7585.

Mejías C, Martín J, Santos JL, Aparicio I, Alonso E (2021) Trends in Environ. Anal. Chem. 30: e00125.

Ortiz de García SA, Pinto Pinto G, García-Encina PA, Irusta-Mata R (2014) Ecotoxicology 23: 1517-1533.

Sörengård M, Campos-Pereira H, Ullberg M, Lai FY, Golovko O, Ahrens L (2019) Chemosphere 234: 931-941.

Spanjers H, Vanrolleghem PA (2016) IWA Publishing, London, UK.

Szabová P, Mackulak T, Vojs-Staňová A, Grabicová K, Varjúová D, Bodík I (2021) Vodní hospodářství 71: 8-12.

Thomaidi VS, Stasinakis AS, Borova VL, Thomaidis NS (2015) J. Hazard. Mater. 283: 740-747.

Thomaidi VS, Stasinakis AS, Borova VL, Thomaidis NS (2016) Sci. Total Environ. 548: 280-288.

Tominaga FK, dos Santos Batista AP, Silva Costa Teixeira AC, Borrely SI (2018) J. Environ. Chem. Eng. 6: 4605-4611.

Vasiliadou IA, Molina R, Martinez F, Melero JA, Stathopoulou PM, Tsiamis G (2018) Sci. Total Environ. 630: 809-819.

Xia Z, Xiao-Chun W, Zhong-Lin C, Hao X, Qing-Fang Z (2015) Appl. Microbiol. Biotechnol. 99: 425-433.

Xing BS and Jin RC (2018) Chemosphere 200: 437-445.

Yang Y, Ok YS, Kim KH, Kwon EE, Tsang YF (2017) Sci. Total. Environ. 596-597: 303-320. 